\title{
Effect of Cold Plasma on Quality Retention of Fresh-Cut Produce
}

\author{
Hadi Bagheri ${ }^{1}{ }^{1}$ and Sepideh Abbaszadeh $\mathbb{D I}^{1,2}$ \\ ${ }^{1}$ Health Research Center, Life Style Institute, Baqiyatallah University of Medical Sciences, Tehran, Iran \\ ${ }^{2}$ Department of Nutrition and Food Hygiene, Faculty of Health, Baqiyatallah University of Medical Sciences, Tehran, Iran
}

Correspondence should be addressed to Hadi Bagheri; bagherihadi51@yahoo.com

Received 24 September 2020; Revised 18 November 2020; Accepted 25 November 2020; Published 7 December 2020

Academic Editor: Giorgia liguori

Copyright ( $\odot 2020$ Hadi Bagheri and Sepideh Abbaszadeh. This is an open access article distributed under the Creative Commons Attribution License, which permits unrestricted use, distribution, and reproduction in any medium, provided the original work is properly cited.

\begin{abstract}
In recent years, the consumption of the fresh-cut products has been increased due to the consumers' lifestyle and awareness. However, maintaining the quality and nutritional value of these products during storage is being difficult in comparison to whole fruits and vegetables. In actual, the procedures used in the fresh-cut industry may intensify the deterioration caused by physical damage by minimal processing. Commonly, the quality degradation, discolouration, loss of moisture, loss of firmness, microbial load increase, and loss of nutrients and flavor occur in the fresh-cut product after minimal processing. To maintain the quality and increase the shelf-life of the fresh-cut product, it is necessary to use various techniques, including physical, chemical, and nondestructive processes. In this review, first, an introduction to minimal processing and its effect on fresh-cut product quality was expressed, and then, the methods used to maintain fresh-cut product quality after minimal processing were reviewed. Finally, the effect of cold plasma on the qualitative characteristics in some fresh-cut products was investigated. The review showed that cold plasma treatments can significantly inhibit microorganisms and extend the shelf-life of fresh-cut products. In addition, no or minimal impacts were observed on physicochemical and organoleptic quality attributes of the treated fresh-cut products. Therefore, the use of cold plasma is promising for the fresh-cut industry.
\end{abstract}

\section{Introduction}

Due to alteration in lifestyles, the consumption of the fresh-cut product (FCP) has been increased in the last decade $[1,2]$. Ready-to-eat, appealing, nutritious, and safe are the prominent features of these products [3]. The International Fresh-Cut Produce Association (IFPA) defines fresh-cut products as fruits or vegetables that have been trimmed and/or cut into a $100 \%$ usable product which is packaged to offer consumers high nutrition, convenience, and flavor while still maintaining freshness [4]. FCP as a novel and attractive product has attracted the most attention and led to the ever-growing freshcut industry and need to develop a novel method to reduce the adverse effects of the processing and maintain their fresh-cut features [5]. These products are very vulnerable due to the minimal processes used in their preparations against corruption and microbial contamination. Minimal processing of fruits and vegetables includes different processing steps such as washing, peeling, cutting, grating or slicing, and disinfection (Figure 1), which are used to obtain the ready-to-eat product [6].
Minimal processing by removing the natural protection (skin) and destroying the internal compartmentalization led them to be much more perishable than when the original product is intact [7]. Minimal processing of the product stimulates biochemical reactions (surface browning, softening, and loss of texture), physiological ageing (dehydration, increasing respiration rate, increasing ethylene production, and loss of appearance), mechanical damage (dehydration and decay), and microbial growth (spoilage and pathogens). As a result of these reactions, the quality of the product reduced (Figure 2), which leads to a minimal shelf-life [3]. As FCP is highly perishable, storage in suitable packaging and cold conditions are essential. However, packaging and cold conditions were not enough to preserve FCP quality at optimum levels during the storage period. Therefore, the appropriate technologies, along with refrigeration, are needed. Some of the conventional methods such as modified atmosphere packaging (MAP) [8], edible coatings [9], and ozone [10] are used to maintain the FCP quality to prevent biochemical and biological complications due to physical damage. These techniques have 


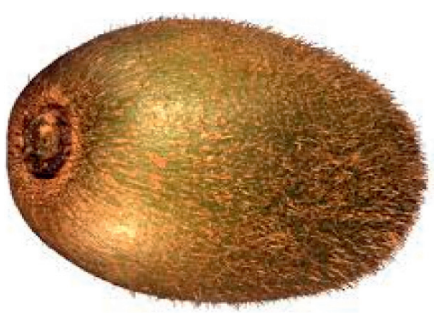

(a)

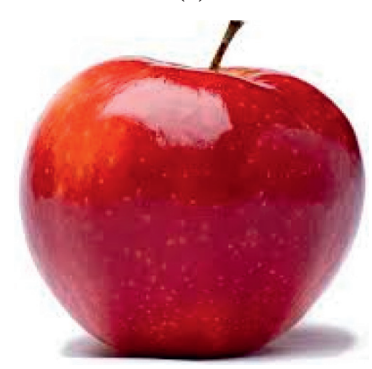

(d)

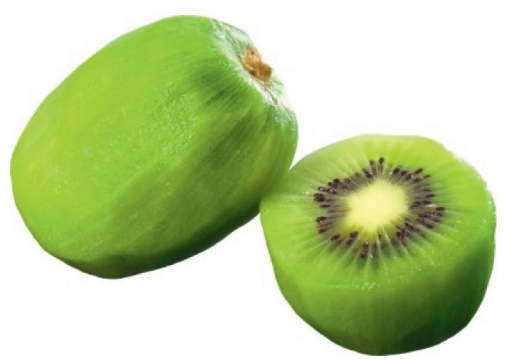

(b)

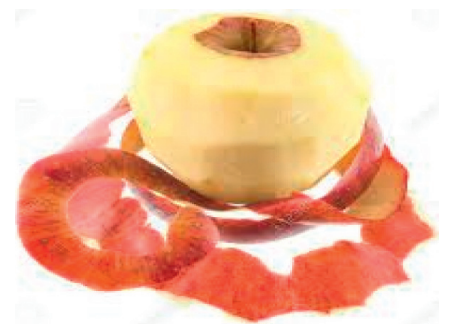

(e)

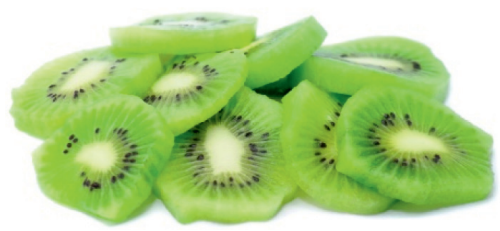

(c)

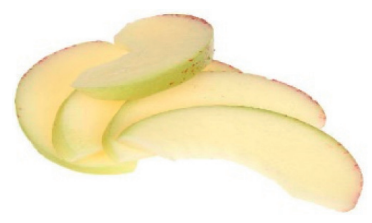

(f)

FIgURE 1: Minimal processing of fresh fruits and vegetables includes washing, peeling, and cutting.

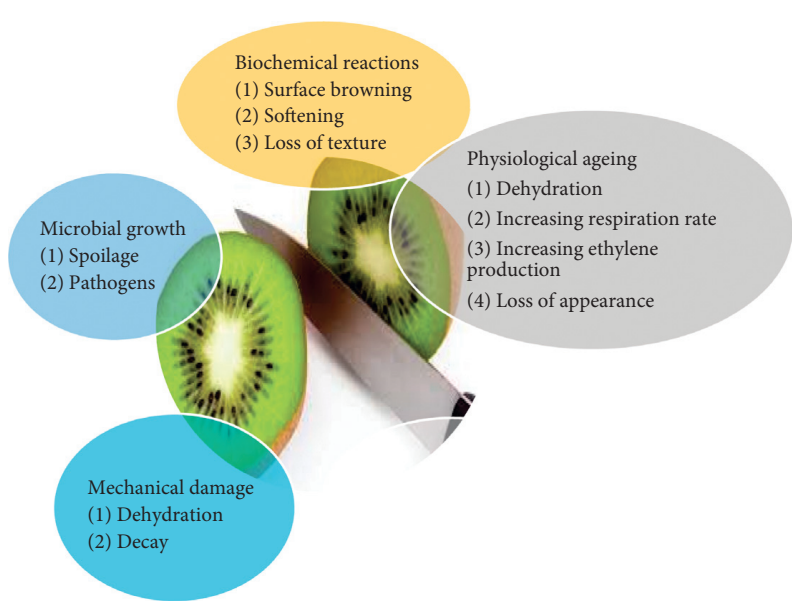

FIGURE 2: Effect of minimal processing on the decay and shelf-life of fresh fruits.

technological and economic disadvantages. These methods are primarily being used to preserve colour, texture, and delay of senescence phenomena caused by tissue-injury reactions; however, these methods are not able to disinfect the FCP.

The exponential growth in demand for FCP has led researchers to develop new nonthermal methods to maintain the desired fresh properties of FCP and increase shelf-life. Therefore, there is a vital need for advanced postharvest technology. Some of the nonthermal methods as disinfection technologies such as UV light and ultrasound have been applied to improve the shelf-life in FCP [11]. Nevertheless, these methods have fundamental disadvantages in cost of items, potential risks, and maintaining control, which limits their practical application on a large scale.

A new alternative that has recently been developed to improve shelf-life is cold plasma. Plasma is known as the fourth state of matter and is produced by the induction of energy into the gas mixture and includes the ionization of the gas and the formation of active components such as radicals, charged particles, and ultraviolet radiation [6]. Cold plasma is formed by microwave (MV), radio frequency (RF), direct current (DC), and alternating current (AC). It has been used in a variety of setups, including dielectric barrier, jet plasma, and corona discharges [12]. Among all the unique features of cold plasma, the most important feature seems to be the microbial inactivation by reactive oxygen and nitrogen species [13]. Researchers identified microbial decontamination of nonthermal plasma on the number of fruits and vegetables $[14,15]$. Also, recently inactivate endogenous enzymatic activity in fresh-cut products by cold plasma has attracted the attention of researchers [16].

The application of cold plasma is a new pattern in the fresh-cut industry and a novel technology to reduce microbial load at the FCP [17, 18] (Figure 3). Therefore, the potential use of cold plasma for the fresh-cut industry is widespread, and it has unique potential for FCP treatment.

There has been no dedicated reference on the topic of cold plasma technologies and their potential applications for fresh-cut produce. This review aimed to introduce cold plasma for preservation of fresh-cut produce. First, the cold plasma technology for the increased shelf-life of fresh-cut produce was present, and then the effect of cold plasma on some quality parameters of the fresh-cut produce was reviewed.

\section{Decontamination of FCP with Cold Plasma}

Cold plasma has been used for fresh-cut product decontamination such as apples, melons, lettuce, and mangoes $[6,15,16,19]$. Among the new application cold plasma for fresh-cut product decontamination summarized in Table 1, Ziuzina et al. [28] showed that the use of cold plasma for 120 


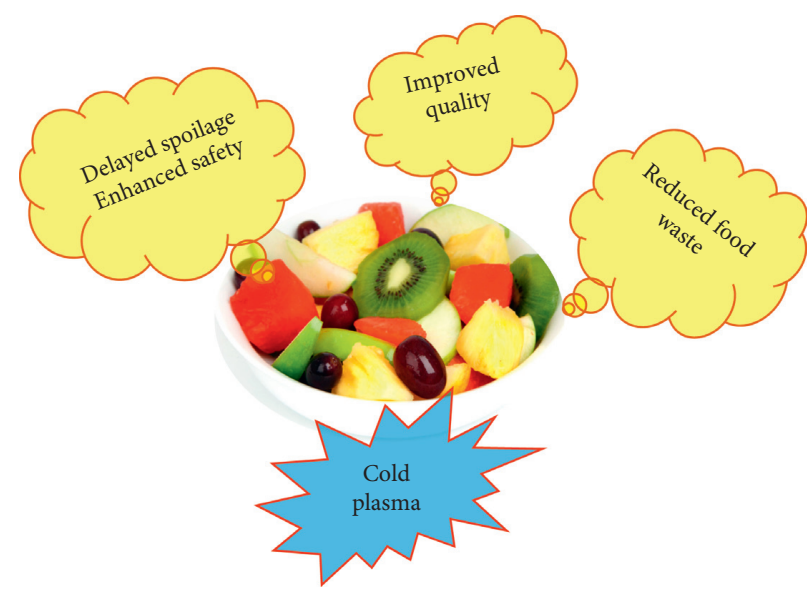

Figure 3: The influence of cold plasma on the quality and safety of FCP.

TABLE 1: Various cold plasma systems used for decontamination of different FCP.

\begin{tabular}{|c|c|c|c|}
\hline FCP & Cold plasma systems & Salient results & References \\
\hline $\begin{array}{l}\text { Cucumber } \\
\text { slice } \\
\text { Carrot slice } \\
\text { Pear slice }\end{array}$ & $\begin{array}{l}\text { Atmospheric pressure cold } \\
\text { plasma, microjet }\end{array}$ & $\begin{array}{l}\text { Effective inactivation was achieved on sliced fruits and vegetables } \\
\text { after 1st plasma treatment }\end{array}$ & Wang et al. [20] \\
\hline $\begin{array}{l}\text { Mangos } \\
\text { Melons }\end{array}$ & $\begin{array}{c}\text { Cold atmospheric plasma } \\
\text { system }\end{array}$ & $\begin{array}{l}\text { Cold plasma has potential in decontaminating the skins of soft } \\
\text { fruits such as mangoes and melons }\end{array}$ & Perni et al. [21] \\
\hline Bananas & $\begin{array}{l}\text { Atmospheric pressure } \\
\text { pulsed cold plasma }\end{array}$ & $\begin{array}{l}\text { This study demonstrated that the cold plasma technique has the } \\
\text { potential to prolong the shelf-life of bananas }\end{array}$ & Trivedi et al. [22] \\
\hline $\begin{array}{l}\text { Fresh-cut } \\
\text { cucumbers }\end{array}$ & $\begin{array}{l}\text { Atmospheric-pressure } \\
\text { low-temperature plasma }\end{array}$ & $\begin{array}{l}\text { The results showed that the E. coli cell morphology was changed } \\
\text { due to the charged particles }\end{array}$ & Sun et al. [23] \\
\hline $\begin{array}{l}\text { Fresh-cut } \\
\text { kiwifruit }\end{array}$ & $\begin{array}{c}\text { Atmospheric double- } \\
\text { barrier discharge plasma }\end{array}$ & $\begin{array}{l}\text { No significant changes in antioxidants content and antioxidant } \\
\text { activity were observed among treated samples and control ones. }\end{array}$ & Ramazzina et al. [24] \\
\hline $\begin{array}{l}\text { Spinach } \\
\text { Lettuce } \\
\text { Tomato } \\
\text { Potato }\end{array}$ & $\begin{array}{l}\text { Nonthermal low pressure } \\
\text { oxygen plasma }\end{array}$ & $\begin{array}{l}\text { This study confirms that nonthermal oxygen plasma can be a new } \\
\text { effective method of sanitization for fresh produce }\end{array}$ & Zhang et al. [25] \\
\hline $\begin{array}{l}\text { Lettuce } \\
\text { Carrot }\end{array}$ & $\begin{array}{l}\text { Atmospheric pressure cold } \\
\text { plasma }\end{array}$ & $\begin{array}{l}\text { Cold plasma represents a potential technology for disinfection of } \\
\text { fruits and vegetables without important changes in physical } \\
\text { characteristics }\end{array}$ & $\begin{array}{l}\text { Bermúdez-Aguirre et al. } \\
\qquad[26]\end{array}$ \\
\hline $\begin{array}{l}\text { Carrot } \\
\text { Lamb's lettuce } \\
\end{array}$ & Microwave cold plasma & $\begin{array}{l}\text { The investigations showed a possible inactivation of seven } \\
\text { different microorganisms with cold plasma }\end{array}$ & Schnabel et al. [27] \\
\hline $\begin{array}{l}\text { Fresh-cut } \\
\text { apples }\end{array}$ & $\begin{array}{l}\text { Dielectric barrier discharge } \\
\text { plasma }\end{array}$ & $\begin{array}{l}\text { Promising results have been obtained regarding enzymatic } \\
\text { browning inhibition and a specific effect on the reduction of } \\
\text { polyphenol oxidase activity on the apple slices has been found }\end{array}$ & Tappi et al. [16] \\
\hline $\begin{array}{l}\text { Fresh-cut } \\
\text { melon }\end{array}$ & $\begin{array}{l}\text { Direct-barrier discharge } \\
\text { plasma }\end{array}$ & $\begin{array}{l}\text { A significant increase in microbial shelf-life was achieved } \\
\text { following the } 15+15 \text { min plasma treatment }\end{array}$ & Tappi et al. [6] \\
\hline
\end{tabular}

seconds lead to reduce Salmonella, E. coli, and L. monocytogenes to undetectable levels on cherry tomatoes.

Fresh strawberries were treated with in-package DBD plasma system, and the results showed a 2-log decrease in microbial load (aerobic mesophilic bacteria, yeast, and mold) due to cold plasma treatment [29]. Niemira and Sites [15] studied the inactivation of Escherichia coli and Salmonella Stanley pathogens using gliding arc cold plasma. The results of this study showed that these two pathogens were inactivated using cold plasma. The intensity of inactivation of these two pathogens increased with increasing gas flow rate. The growth of Salmonella spp., E. coli, and Listeria monocytogenes as spoilage microbes and pathogens has been reported in the fresh-cut melon during storage [6]. Tappi et al. [6] investigated the stabilization of fresh-cut melon using cold plasma. The results show that cold plasma is very efficient to maintain the quality of fresh-cut melons.

The effects of cold plasma on mango and melon with four different pathogens were investigated by Perni et al. [21]. The rate of inactivation of the four pathogens was different, but all four pathogens were inactivated after several minutes of applying the cold plasma. 
Cold plasma significantly inactivated Salmonella Stanley and E. coli O157:H7 (inoculated at apple surfaces), but it did not hurt the appearance of the apple [15]. Due to the high moisture content in the apple fruit, it has a concise shelf-life, and to increase its shelf-life, it is necessary to use different preservation methods. These results emphasize that cold plasma as a nonthermal process can effectively destroy human pathogens and make apple fruit healthy.

Trivedi et al. [22] studied shelf-life of bananas by cold plasma. Bananas are one of the best tropical fruits, and about 1.4 million bananas are wasted each day due to their high perishability. The results showed that cold plasma can increase the shelf-life of bananas by inhibiting the growth of pathogens compared to conventional methods [22].

FCP is very highly susceptible to loss of sensory, microbial, and nutritional quality, therefore, maintaining the quality characteristics of these products is a very significant challenge. Thus, the use of cold plasma has been proposing to preserve and improve the quality of FCP (Table 1). Cold plasma is a novel, nonthermal technology which has shown good potential for FCP decontamination. However, most of the research is largely focused on microbial inactivation studies, with limited emphasis on quality properties. Cold plasma processing has been shown to affect the quality attributes of the FCP during treatment as well as in storage. Therefore, in this review, we tried to investigate the effect of cold plasma on FCP quality characteristics.

\section{Effect of Cold Plasma on Quality Parameters}

The quality of fresh-cut products is a combination of parameters including appearance, texture, flavor, and nutritional value [30]. Consumers judge the quality of fresh-cut fruit and vegetables on the basis of appearance and freshness at the time of purchase. However, subsequent purchases depend upon the consumer's satisfaction in terms of texture and flavor of the product. Consumers are also interested in the nutritional quality and safety of fresh-cut products [31]. Cold plasma is a novel technology used for decontaminating fresh-cut produce. This technology may facilitate the maintenance of high-quality food products due to antimicrobial properties. However, due to the existence of reactive species, cold plasma can also react with nearly all food constituents, affecting physicochemical (for example, $\mathrm{pH}$, carbohydrate, vitamins, anthocyanin, and respiration rate) and organoleptic (for example, taste, colour, and texture) attributes of various fresh produce $[30,31]$. Therefore, it is important to study the effect of plasma on quality characteristics.

3.1. Respiration Rate. The respiration rate of fresh-cut produce is one of the most critical factors in maintaining quality, and one of the most common replies to the damage is respiration. It is considered as a main index of the product shelf-life [32]. The rate of respiration increased after cutting due to the energized state of all living tissues. Depending on the degree of cutting of the product and the storage temperature, the rate respiration in fresh-cut produce may vary between 1.2 and 7.0 [2]. Therefore, after minimal processing similar to the ripening process, the increased respiration creates energy and carbon skeletons for the anabolic reactions [33]. Cellular respiration is a set of metabolic reactions and processes that involves the oxidation of large organic molecules (starch, sugar, and organic acids) to smaller products $\left(\mathrm{CO}_{2}\right.$ and $\left.\mathrm{H}_{2} \mathrm{O}\right)$, along with releasing the energy (ATP and heat), and this energy is used by the cell for synthetic reactions [34]. Respiration rate is often a good indicator of the shelf-life of products, and as the respiration rate increases, the shelf-life of the product decreases [35]. Also, an increased rate of ethylene production in response to minimal processing may stimulate respiration and leads to faster senescence and deterioration of vegetative tissues. Therefore, the respiration rate should be reduced with appropriate methods to increase the shelf-life of fresh-cut produce. Misra et al. [34] reported the respiration rate decrease during the storage time for the control as well as the $\mathrm{CP}$-treated tomatoes. At the end of storage period, the respiration rates were similar for the control and CP-treated tomatoes. The results of Tappi et al. [16] showed that the plasma treatment can cause an alteration of the cellular respiratory pathway. In addition, Misra et al. [36] explored cold plasma treatment for postharvest strawberries in modified atmosphere packaging and indicated no significant increase in respiration rate.

3.2. Firmness. The maximum force required to pierce the sample is used as a firmness indicator and consumers prefer to buy firm fresh-cut fruits. The textural characteristic, especially the firmness, is a critical quality parameter because it has a significant impact on product acceptance. The fresh agricultural product has a firm and tender texture and experiences softening of the texture during storage [37]. Firmness reduction is associated with fresh-cut product storage and is regarded as a sign of declining quality and deterioration [38]. Tappi et al. [16] reported that cold plasma treatments led to an increase of firmness in fresh-cut apples. The amount of firmness was $18.9 \mathrm{~N}$ for the control and $21.8 \mathrm{~N}$ for plasma-treated samples at $15 \mathrm{kV}$ for $10 \mathrm{~min}$ $(5+5)$. There was no difference between the firmness of fresh-cut melon and kiwifruit slices treated with cold plasma and the control sample. The highest firmness was related to the mushroom treated with cold plasma, which indicates the potential application of this innovative technology in increasing the shelf-life and quality after mushroom harvesting [37].

3.3. Colour Retention. Colour is a critical parameter in the quality of food because it can affect the consumer's decision to buy and is probably the first quality factor that is judged [27]. Colour plays a crucial role in food selection and is one of the most important parameters for the consumer [31]. The appearance of FCP is a determining agent in customer acceptance, and it strongly affects the decision to purchase the product [39]. After minimal processing of fresh produce, the metabolic reactions that stimulate respiration and/or ethylene production lead to some undesirable effects that 
affect consumer acceptability. Browning is one of the most common adverse changes that affect the colour of the product and thus affects the visual quality of fresh products [39]. Enzymatic browning results from oxidation of phenolic compounds catalysed by polyphenol oxidase (PPO) followed by nonenzymatic formation of pigments. Cutting operation promotes the contact between enzymes and their substrates and leads to an immediate increase in the respiration rate and endogenous metabolic activity [40]. Therefore, the browning and discoloration effects are the most common undesirable changes that affect color and consequently affect the visual appearance of fresh-cut produces [39]. In the past, various chemical and physical methods have been used to control the enzymatic browning of fresh-cut fruits. The chemical methods used to destroy enzymes are based on the immersion process. Organic acids are the most common materials used for this study that is applied in combination with calcium salts [38]. The use of edible coatings as a carrier of antibrowning chemical agents to prevent browning has also been extensively investigated by researchers and several scholars have studied the use of modified atmosphere packaging (MAP) for controlling browning reactions [8]. In recent years, various innovative therapies have been tested to control browning reactions in fresh-cut fruits. Currently, among the innovative techniques, cold plasma is used for biological therapies. Tappi et al. [16] reported a significant reduction in PPO activity in fresh-cut Pink Lady apples due to cold plasma treatment. The researchers showed that the activity of a PPO enzyme in the treated samples was about $45 \%$ lower than the untreated sample (control). The reduction of PPO activity may be due to the reaction between enzymes and free radicals.

Table 2 shows the changes in $L *, a *, b *, \Delta E$, and chroma of cold plasma-treated samples. As seen in Table 2, the effect of cold plasma on the changes of colour was variable, which is due to the different types of fruits and vegetables. Cold plasma may stabilize the colour in fruits where the browning reaction occurs, and in fruits containing carotenoids, it may reduce the colour slightly. The accepted mechanism for the observed loss of enzymatic functionality upon plasma exposure is an oxidation of the side-chain amino acids that cause an alteration of the secondary structures of the protein operated by the reactive species. Bermúdez-Aguirre et al. [26] reported that the destruction of carotenoid pigments by reactive species led to significant changes in the colour of cold plasma-treated tomatoes [26].

3.4. $p H$ and Acidity. These two parameters are important to evaluate the freshness in cut fruits and vegetables and strongly are correlated due to the $\mathrm{pH}$ depending on the presence of acidic compounds. Acid content in fresh-cut produce tends to decrease over time, probably due to the organic acid oxidation which occurs with fruit ripening [42]; as a consequence, a pH increase is expected during the storage time. Any drastic change could lead to an undesirable impact on the taste, texture, and shelf-life of the food. However, in the case of fresh fruits and vegetables, there are significant variations due to differences in cultivation practices, varietal differences, environmental parameters, etc. The $\mathrm{pH}$ and acidity changes after plasma treatment were mostly attributed to the interaction of plasma reactive gases with the moisture present in the fresh-cut products $[19,27]$. Oehmigen et al. [43] reported the formation of nitric acid induced by reactive nitrogen species such as NO as the reason for acidification in air plasma treatments. However, many researchers also reported no $\mathrm{pH}$ effect of $\mathrm{CP}$ treatments in food products with buffering capacity $[18,29]$. No significant changes in the acidity and $\mathrm{pH}$ after $\mathrm{CP}$ treatment were reported in cherry tomatoes, blueberry, mandarins, and melon $[6,18,22,34]$.

3.5. Vitamins. The sensitivity of vitamins to different processing techniques is essential to preserve the nutritional properties of the fresh-cut products [30]. While some vitamins, such as riboflavin (B2), pyridoxine (B6), and biotin, are usually stable, others, such as thiamin (B1) and vitamins A, C, and E, are relatively labile [44]. Most of the reported studies on cold plasma treatment of food products have only focused on vitamin C (ascorbic acid) stability. Most of the studies on cold plasma treatment of fresh-cut products have reported no significant reduction in ascorbic acid content after plasma treatment. Ramazzina et al. [24], Oh et al. [45], and Song et al. [46] reported no significant effect on ascorbic acid in kiwifruit, radish sprout, and lettuce, respectively. However, up to $4 \%$ reduction in ascorbic acid content was observed after plasma treatment of cut fruits and vegetables [22]. The degradation of ascorbic acid could be attributed to the reaction with ozone and other oxidizing plasma species during the processing. Sample type, processing time, and plasma gas were critical factors for ascorbic acid degradation. Misra et al. [29] reported a decrease in the ascorbic acid content of cold plasma-treated strawberries. Both applied voltage and treatment time were found to have a significant effect on the ascorbic acid content. There was a statistically significant difference between samples treated at $60 \mathrm{kV}$ than those at $80 \mathrm{kV}$. The reaction of ozone and other oxidizing species of cold plasma with ascorbic acid is proposed to be the major mode of action for the observed loss during processing. Also, Wange et al. [20] have studied vitamin C loss of fresh fruit and vegetable slices (cucumber, carrot, and pear slices) during cold plasma treatment. The vitamin $\mathrm{C}$ loss for the cucumber, carrot, and pear slices was $3.6 \%, 3.2 \%$, and $2.8 \%$, respectively. The slight reduction in vitamin $\mathrm{C}$ content is most likely due to its oxidation by the cold plasma. In addition, vitamin $\mathrm{C}$ is light sensitive [47], so UV generated by plasma may also play an important role in the vitamin $\mathrm{C}$ degradation.

3.6. Antioxidant Activity. Although the antioxidant activity is not a direct quality attribute used in the fresh-cut industry, it is a close indicator of various polyphenols, flavonoids, and flavanols present in the fresh-cut products [30]. The reported results on the effects of $\mathrm{CP}$ treatment on the phenolic contents of the food products have a wide degree of variation. A decrease in the total phenols was reported in lamb's lettuce [48]. No significant effect in apples [32] but a significant increase in blueberries [41] was also reported. No significant changes in the antioxidant capacity after $\mathrm{CP}$ 
TABLE 2: The $L *, a *, b *, \Delta E$, and chroma values for various FCP after cold plasma treatment.

\begin{tabular}{|c|c|c|c|c|c|c|}
\hline FCP & $\mathrm{CP}$ treatment & $L *$ & $a *$ & $b *$ & $\Delta E \Delta \mathrm{E}$ & References \\
\hline \multirow{2}{*}{ Banana } & $C$ & $50.2 \pm 4.4$ & $4.9 \pm 1.2$ & $34.8 \pm 3.7$ & - & \multirow{2}{*}{ Trivedi et al. [22] } \\
\hline & $\mathrm{PT}$ & $53.9 \pm 3.9$ & $5.5 \pm 1.4$ & $34.0 \pm 3.0$ & - & \\
\hline \multirow{2}{*}{ Cucumber 1} & $C$ & $63.78 \pm 0.25$ & $-6.07 \pm 0.10$ & $16.61 \pm 0.10$ & 0 & \multirow{2}{*}{ Sun et al. [23] } \\
\hline & PT & $63.89 \pm 0.23$ & $-5.98 \pm 0.15$ & $16.63 \pm 0.13$ & $0.73 \pm 0.25$ & \\
\hline \multirow{2}{*}{ Cucumber 2} & $C$ & 63.57 & -6.25 & 20.53 & 0 & \\
\hline & PT & 63.15 & -6.17 & 19.76 & $0.67 \pm 0.12$ & \\
\hline \multirow{2}{*}{ Carrot } & $C$ & 55.49 & 20.87 & 24.60 & 0 & \multirow{2}{*}{ Wang et al. [22] } \\
\hline & $\mathrm{PT}$ & 54.81 & 20.01 & 23.30 & $1.51 \pm 0.63$ & \\
\hline \multirow{2}{*}{ Pear } & $C$ & 68.51 & -0.55 & 6.69 & 0 & \\
\hline & $\mathrm{PT}$ & 69.14 & -0.25 & 7.83 & $1.34 \pm 0.09$ & \\
\hline \multirow{2}{*}{ Blueberries } & $C$ & $48.90 \pm 0.73$ & $0.30 \pm 0.02$ & $-1.19 \pm 0.03$ & - & \multirow{2}{*}{ Sarangapani et al. [41] } \\
\hline & $\mathrm{PT}$ & $43.76 \pm 0.86$ & $0.23 \pm 0.06$ & $-1.43 \pm 0.06$ & - & \\
\hline \multirow{2}{*}{ Melon } & $C$ & $57.9 \pm 4.7$ & $20.8 \pm 1.7$ & $46.6 \pm 3.1$ & - & \multirow{2}{*}{ Tappi et al. [6] } \\
\hline & PT & $54.4 \pm 3.5$ & $17.5 \pm 2.7$ & $34.0 \pm 3.7$ & - & \\
\hline
\end{tabular}

C, control; PT, plasma treatment.

treatment was reported in radish sprouts, kiwifruits, and red chicory $[32,45,49]$. These studies show that the type of freshcut products, plasma generation source, mode of exposure, and treatment parameters are critical in controlling the effects of CP on the antioxidant activity of food products. Also, Ramazzina et al. [24] used ABTS, DPPH, and FRAP assays to observe the effect of DBD plasma on the antioxidant activity and antioxidant contents of kiwifruit. The result showed no alteration in all the assays conducted after the NTP treatment. Generally, plasma-ROS should have caused oxidation of the phenolic compounds responsible for the antioxidant activity; however, due to the counteractive effect of the tissue response mechanisms in the kiwifruit, the ROS-induced oxidation was impeded [24].

3.7. Sensory Properties. Consumer interest worldwide in the quality of fresh-cut products has increased in recent years. Product quality is a complex issue, since it includes visual characteristics, physical properties such as texture, mineral and vitamin contents, flavor, and other organoleptic characteristics [50]. Appearance, flavor, and freshness of a product can play a principal role in the consumer's decision to purchase it and can influence perception by other senses. However, it is very important to remember that maturity and postharvest treatments, such as cold plasma, can significantly affect the taste and aroma quality of fresh produce [24]. Sensory parameters such as taste, flavor, colour, and texture in cold plasma-treated cherry tomatoes remained at an acceptable level after treatment [51]. Similarly, Srey et al. [52] reported that cold plasma did not cause any statistically significant change in the sensorial quality (colour and texture).

Effects of cold plasma on some of the quality attributes of fresh-cut products are presented in this study. Among the quality attributes, the effect of cold plasma on colour parameters was the most widely studied, probably because colour is the most obvious parameter that directly influences the acceptance by consumers. Cold plasma has been applied for the decontamination of food products, as an alternative to washing procedures with chemicals.
Since the temperature of the product during the treatment is very close to the ambient, this technique can be suitable for the processing of temperature sensitive products such as fresh-cut fruits and vegetables. Moreover, the potential direct application of packed products seems promising $[29,36]$.

\section{Conclusions and Future Perspectives}

Demand for FCF has risen sharply due to the growing consumer concern about their own diets and the supply of highvalue fresh-cut products. However, the minimal process used to get ready the products will intensify the procedure of ripening and exposing the products to microbial contamination; therefore, shelf-life is shortened. In recent years, some studies have already been conducted to lessen the undesirable effects of minimal processing on the quality of FCP. The purpose of these studies would be to increase the shelf-life of the product by preserving the quality characteristics of the product. Therefore, enhanced substitute sanitization approaches and processing methods could be applied for making sure safeness and increasing the shelf-life of FCP. Cold plasma can be an innovative and emerging technology useful for disinfecting foodstuff surfaces. Cold plasma positively affected the visible quality preservation of FCP during storage. Cold plasma is promising for extending the storage life of FCP. Generally, cold plasma is a potential technology for treating FCP to improve their quality and prolong their shelf-life.

However, understanding the effects of cold plasma on the quality changes of FCP is still limited. Considering the high oxidative action of cold plasma, its effect on the bioactive compounds of the fresh-cut fruit tissue has to be deeply studied in order to highlight the nature of gas plasma effect on biochemical tissue response.

\section{Data Availability}

The data used to support the findings of this study are available from the corresponding author upon request. 


\section{Ethical Approval}

The study did not involve any human or animal testing.

\section{Conflicts of Interest}

The authors declare that there are no conflicts of interest.

\section{Acknowledgments}

The authors would like to thank Baqiyatallah University of Medical Sciences, Tehran, Iran.

\section{References}

[1] O. Martin-Belloso and R. S. Fortuny, Advances in Fresh-Cut Fruits and Vegetables Processing, CRC Press, Cleveland, $\mathrm{OH}$, USA, 2010.

[2] G. R. Velderrain-Rodriguez, A. E. Quirós-Sauceda, G. G. Aguilar, M. W. Siddiqui, and J. A. Zavala, "Technologies in fresh-cut fruit and vegetables," in Minimally Processed Foods, pp. 79-103, Springer, Berlin, Germany, 2015.

[3] U. De Corato, "Improving the shelf-life and quality of fresh and minimally-processed fruits and vegetables for a modern food industry: a comprehensive critical review from the traditional technologies into the most promising advancements," Critical Reviews in Food Science and Nutrition, vol. 60, no. 6, pp. 940-975, 2020.

[4] D. Rico, A. B. Martín-Diana, J. M. Barat, and C. Barry-Ryan, "Extending and measuring the quality of fresh-cut fruit and vegetables: a review," Trends in Food Science \& Technology, vol. 18, no. 7, pp. 373-386, 2007.

[5] A. Y. Ramos-Villarroel, N. Aron-Maftei, O. Martín-Belloso, and R. Soliva-Fortuny, "The role of pulsed light spectral distribution in the inactivation of Escherichia coli and Listeria innocua on fresh-cut mushrooms," Food Control, vol. 24, no. 1-2, pp. 206-213, 2012.

[6] S. Tappi, G. Gozzi, L. Vannini et al., "Cold plasma treatment for fresh-cut melon stabilization," Innovative Food Science \& Emerging Technologies, vol. 33, pp. 225-233, 2016.

[7] P. Sharma, V. P. Shehin, N. Kaur, and P. Vyas, "Application of edible coatings on fresh and minimally processed vegetables: a review," International Journal of Vegetable Science, vol. 25, no. 3, pp. 295-314, 2019.

[8] E. Aguayo, C. Requejo-Jackman, R. Stanley, and A. Woolf, "Effects of calcium ascorbate treatments and storage atmosphere on antioxidant activity and quality of fresh-cut apple slices," Postharvest Biology and Technology, vol. 57, no. 1, pp. 52-60, 2010.

[9] M. E. Martiñon, R. G. Moreira, M. E. Castell-Perez, and C. Gomes, "Development of a multilayered antimicrobial edible coating for shelf-life extension of fresh-cut cantaloupe (Cucumis melo L.) stored at $4^{\circ} \mathrm{C}$," LWT-Food Science and Technology, vol. 56, no. 2, pp. 341-350, 2014.

[10] M. V. Selma, A. M. Ibáñez, M. Cantwell, and T. Suslow, "Reduction by gaseous ozone of Salmonella and microbial flora associated with fresh-cut cantaloupe," Food Microbiology, vol. 25, no. 4, pp. 558-565, 2008.

[11] M. P. Palekar, T. M. Taylor, J. E. Maxim, and A. Castillo, "Reduction of Salmonella enterica serotype Poona and background microbiota on fresh-cut cantaloupe by electron beam irradiation," International Journal of Food Microbiology, vol. 202, pp. 66-72, 2015.
[12] H. Bagheri, S. Abbaszadeh, and A. Salari, "Optimization of decontamination conditions for Aspergillus flavus inoculated to military rations snack and physicochemical properties with atmospheric cold plasma," Journal of Food Safety, Article ID e12850, 2020, In press.

[13] E. Takai, K. Kitano, J. Kuwabara, and K. Shiraki, "Protein inactivation by low-temperature atmospheric pressure plasma in aqueous solution," Plasma Processes and Polymers, vol. 9, no. 1, pp. 77-82, 2012.

[14] F. J. Critzer, K. Kelly-Wintenberg, S. L. South, and D. A. Golden, "Atmospheric plasma inactivation of foodborne pathogens on fresh produce surfaces," Journal of Food Protection, vol. 70, no. 10, pp. 2290-2296, 2007.

[15] B. A. Niemira and J. Sites, "Cold plasma inactivates Salmonella Stanley and Escherichia coli O157: H7 inoculated on golden delicious applest," Journal of Food Protection, vol. 71, no. 7, pp. 1357-1365, 2008.

[16] S. Tappi, A. Berardinelli, L. Ragni, M. Dalla Rosa, A. Guarnieri, and P. Rocculi, "Atmospheric gas plasma treatment of fresh-cut apples," Innovative Food Science and Emerging Technologies, vol. 21, pp. 114-122, 2014.

[17] B. A. Niemira, "Cold plasma decontamination of foods," Annual Review of Food Science and Technology, vol. 3, no. 1, pp. 125-142, 2012.

[18] M. Y. Won, S. J. Lee, and S. C. Min, "Mandarin preservation by microwave-powered cold plasma treatment," Innovative Food Science and Emerging Technologies, vol. 39, pp. 25-32, 2017.

[19] A. Sharma, G. Collins, and A. Pruden, "Differential gene expression in Escherichia coli following exposure to nonthermal atmospheric pressure plasma," Journal of Applied Microbiology, vol. 107, no. 5, pp. 1440-1449, 2009.

[20] R. X. Wang, W. F. Nian, H. Y. Wu et al., "Atmosphericpressure cold plasma treatment of contaminated fresh fruit and vegetable slices: inactivation and physiochemical properties evaluation," The European Physical Journal D, vol. 66, no. 10, p. 276, 2012.

[21] S. Perni, D. W. Liu, G. Shama, and M. G. Kong, "Cold atmospheric plasma decontamination of the pericarps of fruit," Journal of Food Protection, vol. 71, no. 2, pp. 302-308, 2008.

[22] M. H. Trivedi, K. Patel, H. Itokazu et al., "Enhancing shelf life of bananas by using atmospheric pressure pulsed cold plasma treatment of the storage atmosphere," Plasma Medicine, vol. 9, no. 1, 2019.

[23] Y. Sun, Z. Zhang, and S. Wang, "Study on the bactericidal mechanism of atmospheric-pressure low-temperature plasma against Escherichia coli and its application in fresh-cut cucumbers," Molecules, vol. 23, no. 4, p. 975, 2018.

[24] I. Ramazzina, A. Berardinelli, F. Rizzi et al., "Effect of cold plasma treatment on physico-chemical parameters and antioxidant activity of minimally processed kiwifruit," Postharvest Biology and Technology, vol. 107, pp. 55-65, 2015.

[25] M. Zhang, J. K. Oh, L. Cisneros-Zevallos, and M. Akbulut, "Bactericidal effects of nonthermal low-pressure oxygen plasma on S. typhimurium LT2 attached to fresh produce surfaces," Journal of Food Engineering, vol. 119, no. 3, pp. 425-432, 2013.

[26] D. Bermúdez-Aguirre, E. Wemlinger, P. Pedrow, G. BarbosaCánovas, and M. Garcia-Perez, "Effect of atmospheric pressure cold plasma (APCP) on the inactivation of Escherichia coli in fresh produce," Food Control, vol. 34, no. 1, pp. 149-157, 2013.

[27] U. Schnabel, R. Niquet, O. Schlüter, H. Gniffke, and J. Ehlbeck, "Decontamination and sensory properties of microbiologically contaminated fresh fruits and vegetables by 
microwave plasma processed air (PPA)," Journal of Food Processing and Preservation, vol. 39, no. 6, pp. 653-662, 2015.

[28] D. Ziuzina, S. Patil, P. J. Cullen, K. M. Keener, and P. Bourke, "Atmospheric cold plasma inactivation of Escherichia coli, Salmonella enterica serovar Typhimurium and Listeria monocytogenes inoculated on fresh produce," Food Microbiology, vol. 42, pp. 109-116, 2014.

[29] N. N. Misra, S. K. Pankaj, J. M. Frias, K. M. Keener, and P. J. Cullen, "The effects of nonthermal plasma on chemical quality of strawberries," Postharvest Biology and Technology, vol. 110, pp. 197-202, 2015.

[30] S. K. Pankaj, Z. Wan, and K. M. Keener, "Effects of cold plasma on food quality: a review," Foods, vol. 7, no. 1, p. 4, 2018.

[31] A. I. Muhammad, Q. Xiang, X. Liao, D. Liu, and T. Ding, "Understanding the impact of nonthermal plasma on food constituents and microstructure-A review," Food and Bioprocess Technology, vol. 11, no. 3, pp. 463-486, 2018.

[32] B. B. Surjadinata and L. Cisneros-zevallos, "Modeling woundinduced respiration of fresh-cut carrots (Daucus carota L.)," Journal of Food Science, vol. 68, no. 9, pp. 2735-2740, 2003.

[33] M. Helena Gomes, R. M. Beaudry, D. P. F. Almeida, and F. Xavier Malcata, "Modelling respiration of packaged freshcut "Rocha" pear as affected by oxygen concentration and temperature," Journal of Food Engineering, vol. 96, no. 1, pp. 74-79, 2010.

[34] N. N. Misra, K. M. Keener, P. Bourke, J. P. Mosnier, and P. J. Cullen, "In-package atmospheric pressure cold plasma treatment of cherry tomatoes," Journal of Bioscience and Bioengineering, vol. 118, no. 2, pp. 177-182, $2014 \mathrm{a}$.

[35] G. L. Robertson, "Food packaging principles and practice second edition," Food Science and Technology-New YorkMarcel Dekker-, vol. 152, 2006.

[36] N. N. Misra, T. Moiseev, S. Patil et al., "Cold plasma in modified atmospheres for post-harvest treatment of strawberries," Food and Bioprocess Technology, vol. 7, no. 10, pp. 3045-3054, 2014b.

[37] M. Cullen, F. H. Sheu, M. J. Tsai, and Y. H. Chu, "The effects of dielectric barrier discharge plasma gas and plasma-activated water on texture, color, and bacterial characteristics of shiitake mushroom," Journal of Food Processing and Preservation, Article ID e14316, vol. 44, no. 1, pp. 1-9, 2019.

[38] Z. U. Khan, G. Aisikaer, R. U. Khan et al., "Effects of composite chemical pretreatment on maintaining quality in button mushrooms (Agaricus bisporus) during postharvest storage," Postharvest Biology and Technology, vol. 95, pp. 36-41, 2014.

[39] P. M. A. Toivonen and D. A. Brummell, "Biochemical bases of appearance and texture changes in fresh-cut fruit and vegetables," Postharvest Biology and Technology, vol. 48, no. 1, pp. 1-14, 2008.

[40] R. C. Soliva-Fortuny and O. Martín-Belloso, "New advances in extending the shelf-life of fresh-cut fruits: a review," Trends in Food Science \& Technology, vol. 14, no. 9, pp. 341-353, 2003.

[41] C. Sarangapani, G. O’Toole, P. J. Cullen, and P. Bourke, "Atmospheric cold plasma dissipation efficiency of agrochemicals on blueberries," Innovative Food Science \& Emerging Technologies, vol. 44, pp. 235-241, 2017.

[42] O. Lamikanra, J. C. Chen, D. Banks, and P. A. Hunter, "Biochemical and microbial changes during the storage of minimally processed cantaloupe," Journal of Agricultural and Food Chemistry, vol. 48, no. 12, pp. 5955-5961, 2000.

[43] K. Oehmigen, M. Hähnel, R. Brandenburg, C. Wilke, K. D. Weltmann, and T. Von Woedtke, "The role of acidification for antimicrobial activity of atmospheric pressure plasma in liquids," Plasma Processes and Polymers, vol. 7, no. 3-4, pp. 250-257, 2010.

[44] A. P. Dionísio, R. T. Gomes, and M. Oetterer, "Ionizing radiation effects on food vitamins: a review," Brazilian Archives of Biology and Technology, vol. 52, no. 5, pp. 1267-1278, 2009.

[45] Y. J. Oh, A. Y. Song, and S. C. Min, "Inhibition of Salmonella typhimurium on radish sprouts using nitrogen-cold plasma," International Journal of Food Microbiology, vol. 249, pp. 6671, 2017.

[46] A. Y. Song, Y. J. Oh, J. E. Kim, K. B. Song, D. H. Oh, and S. C. Min, "Cold plasma treatment for microbial safety and preservation of fresh lettuce," Food Science and Biotechnology, vol. 24, no. 5, pp. 1717-1724, 2015.

[47] S. Helgadóttir, S. Pandit, V. R. Mokkapati, F. Westerlund, P. Apell, and I. Mijakovic, "Vitamin C pretreatment enhances the antibacterial effect of cold atmospheric plasma," Frontiers in Cellular and Infection Microbiology, vol. 7, p. 43, 2017.

[48] F. Grzegorzewski, J. Ehlbeck, O. Schlüter, L. W. Kroh, and S. Rohn, "Treating lamb's lettuce with a cold plasma - influence of atmospheric pressure Ar plasma immanent species on the phenolic profile of Valerianella locusta," LWT - Food Science and Technology, vol. 44, no. 10, pp. 2285-2289, 2011.

[49] F. Pasquali, A. C. Stratakos, A. Koidis et al., "Atmospheric cold plasma process for vegetable leaf decontamination: a feasibility study on radicchio (red chicory, Cichorium intybus L.)," Food Control, vol. 60, pp. 552-559, 2016.

[50] D. M. Trevisani, J. C. Beaulieu, and R. Shewfelt, "Color, flavor, texture, and nutritional quality of fresh-cut fruits and vegetables: desirable levels, instrumental and sensory measurement, and the effects of processing," Critical Reviews in Food Science and Nutrition, vol. 50, no. 5, pp. 369-389, 2010.

[51] T. Lee, P. Puligundla, and C. Mok, "Intermittent corona discharge plasma jet for improving tomato quality," Journal of Food Engineering, vol. 223, pp. 168-174, 2018.

[52] S. Srey, S. Y. Park, I. K. Jahid, and S. D. Ha, "Reduction effect of the selected chemical and physical treatments to reduce L. monocytogenes biofilms formed on lettuce and cabbage," Food Research International, vol. 62, pp. 484-491, 2014. 